\title{
Corpus luteum in ectopic ovarian tissue miming tubal pregnancy
}

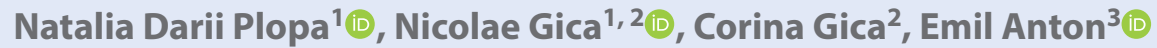 \\ ${ }^{1}$ Department of Gynecology, University of Louvain, CHU Dinant Godinne, Yvoir, Belgium \\ 2"Carol Davila" University of Medicine and Pharmacy, Department of Obstetrics and Gynecology, Bucharest, Romania \\ ${ }^{3}$ University of Medicine and Pharmacology Gr T Popa, Iași, Romania
}

\begin{abstract}
We report an extraordinarily rare case of a pregnant patient with history of multiple ovarian cyst surgery. The corpus luteum developed on an ectopic ovarian tissue, miming an tubal pregnancy. One week later after the diagnostic laparoscopy an intrauterine pregnancy was visualised. Therefore, ectopic ovarian tissue with normal follicular activity may appear after multiple ovarian surgery.
\end{abstract}

Key words: corpus luteum; ectopic ovarian tissue; ectopic pregnancy; tubal pregnancy; ovarian surgery

Ginekologia Polska 2021; 92, 5: 392-393

\section{INTRODUCTION}

Ovarian cyst surgery can lead to fragmentation of the normal ovarian tissue that has the potential of peritoneal implantation, thereafter, becoming ectopic ovarian tissue. Exceptionally this ovarian tissue can be functional and a corpus luteum may be present at this level.

\section{CASE REPORT}

A 33-year-old primipara, primigesta, with a history of multiple ovarian cysts surgery (including the last laparoscopic dermoid cysts excision five years ago), was admitted to the emergency department for severe abdominal pain and a positive pregnancy test. She was at four weeks of amenorrhoea. The human chorionic gonadotropin (HCG) serum concentration, in the emergency department, was $438 \mathrm{mUl} / \mathrm{mL}$. The transvaginal ultrasonography revealed an adnexal right structure of $27.9 \times 13.4 \mathrm{~mm}$ suggestive for ectopic pregnancy and liquid in the Douglas pouch $(20 \times 12 \mathrm{~mm})$ (Fig. $1 \mathrm{~A}, \mathrm{~B})$. In our case the patient required emergency laparoscopy and had no dynamic monitoring of HCG.

During diagnostic laparoscopy, both fallopian tubes and ovaries were normal without corpus luteum. An elongated cystic structure of $3 \times 1.5 \mathrm{~cm}$ corresponding with a corpus luteum developed on the right ectopic ovarian tissue was found miming an extrauterine pregnancy (Fig. 1 C, D). Cytological analysis of intracystic liquid was realized with evidence of hemorrhagic liquid with luteinized granulosa cells. The liquid in the Douglas pouch was serocitrin.

One week later we performed a transvaginal ultrasound and a single intrauterine pregnancy was visualized and currently the patient has 14 weeks of gestation. At that time, the patient gives informed consent for publication.

\section{DISCUSSION AND CONCLUSION}

The incidence of ectopic pregnancy seems to rise especially in developing countries due to pelvic inflammatory disease, endometriosis, smoking and the assisted reproductive techniques [1, 2]. The typical symptoms are unilateral abdominal pain and vaginal bleeding between 6 and 10 weeks of gestation and the diagnosis is confirmed by measurement of serum HCG and ultrasound exam. An anechogenic ultrasonographic adnexal mass is highly suggestive for a corpus luteum and must be distinguished of an ectopic pregnancy that has an endometrium like echogenicity aspect [3].

\section{Corresponding author:}

Nicolae Gica

Department of Gynecology, University of Louvain, CHU Dinant Godinne, Yvoir, Belgium; "Carol Davila” University of Medicine and Pharmacy, Department of Obstetrics and Gynecology,

Bucharest, Romania

e-mail: gica.nicolae@umfcd.ro

This article is available in open access under Creative Common Attribution-Non-Commercial-No Derivatives 4.0 International (CC BY-NC-ND 4.0) license, allowing to download articles and share them with others as long as they credit the authors and the publisher, but without permission to change them in any way or use them commercially. 

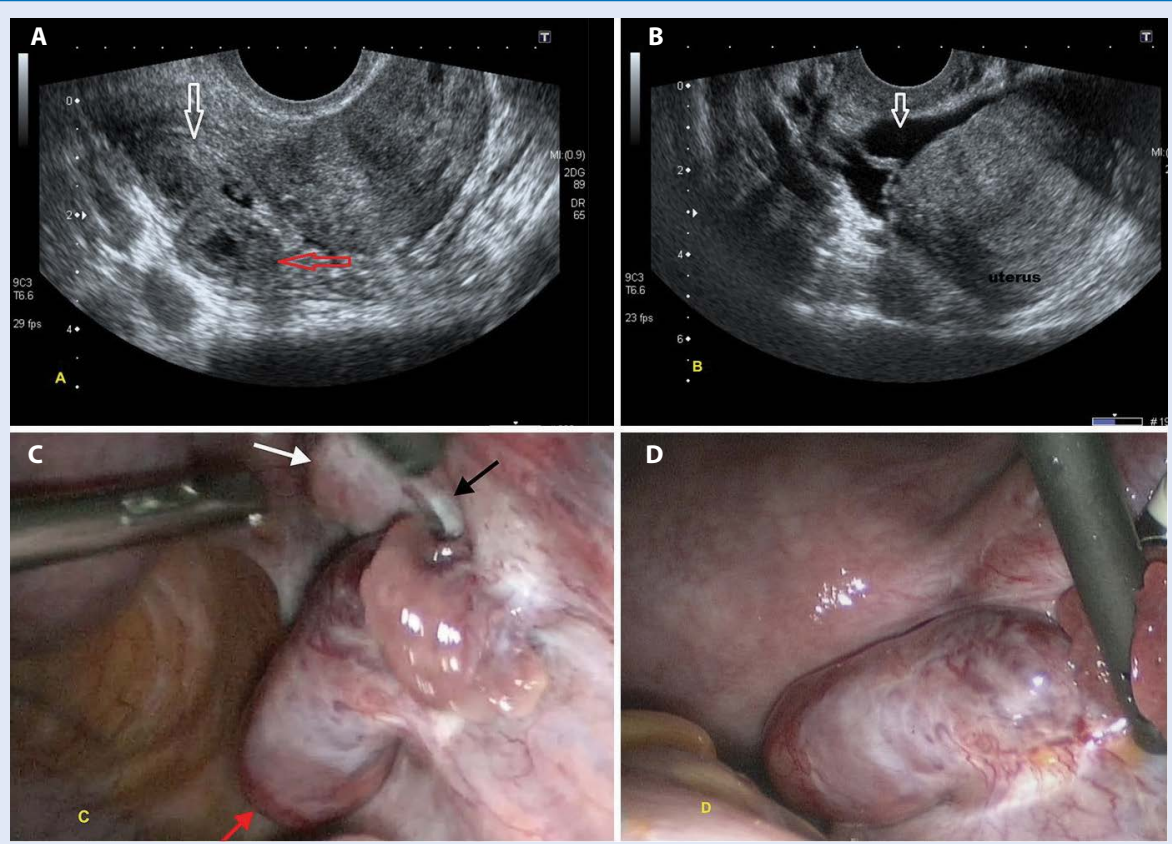

Figure 1. Transvaginal ultrasonography; A. The right ovary. The white arrow shows the right ovary and the red arrow shows the suspected ectopic pregnancy; B. The liquid in the Douglas pouch (white arrow); Laparoscopy; C. The corpus luteum developed on the right ectopic ovarian tissue; D. The red arrows shows the corpus luteum on the ectopic ovarian tissue. The black arrow shows the fallopian tube. The white arrows shows the right ovary

Differential diagnosis may be made with other adnexal masses such as functional cyst, benign pathology, borderline or malignant adnexal disease as well tubal, ovarian or synchronous intrauterine and ectopic pregnancy [4]. Ovarian or tubal torsion may be among the causes of acute pelvic pain [5].

In the case of suspected ectopic pregnancy, the surgery is proposed when the patient have severe pain or signs of complicated ectopic pregnancy. Therefore, in the surgical treatment of an ectopic pregnancy, the most important elements which define the choice of the best treatment are the severity of the disease, the clinical characteristics of the patient and her desire to preserve fertility, all in accordance with the patient desire. In our case to avoid false diagnoses ideally, we should have done a dynamic HCG evolution, but the patient presented with intense abdominal pain at the emergency room, with clinical criteria for an emergency surgical exploration.

When a history of ovarian surgery is known and in the presence of adnexal masses, we must consider the possibility of ovulation of an ectopic tissue that could mimic an ectopic pregnancy.

As far as we know there are no reported cases of corpus luteum in ectopic ovarian tissue.

\section{Authors' contributions}

All authors contributed equally to this article.

\section{Conflict of interest}

There was no potential conflict of interest was reported by the author(s).

\section{REFERENCES}

1. Sivalingam VN, Duncan WC, Kirk E, et al. Diagnosis and management of ectopic pregnancy. J Fam Plann Reprod Health Care. 2011; 37(4): 231-240, doi: 10.1136/jfprhc-2011-0073, indexed in Pubmed: 21727242.

2. Gica N, Panaitescu AM, lancu G, et al. The role of biological markers in predicting infertility associated with non-obstructive endometriosis. Ginekol Pol. 2020; 91(4): 189-192, doi: 10.5603/GP.2020.0039, indexed in Pubmed: 32374018.

3. Stein MW, Ricci ZJ, Novak L, et al. Sonographic comparison of the tubal ring of ectopic pregnancy with the corpus luteum. J Ultrasound Med. 2004; 23(1): 57-62, doi: 10.7863/jum.2004.23.1.57, indexed in Pubmed: 14756354.

4. Gica N, Mustata L, Botezatu R, et al. Management of Borderline Ovarian Tumors: Series of Case Report and Review of the Literature. Indian Journal of Surgery. 2020, doi: 10.1007/s12262-020-02455-w.

5. Laganà AS, Sofo V, Salmeri FM, et al. Oxidative Stress during Ovarian Torsion in Pediatric and Adolescent Patients: Changing The Perspective of The Disease. Int J Fertil Steril. 2016; 9(4): 416-423, doi: 10.22074/ijfs.2015.4598, indexed in Pubmed: 26985329. 